\title{
Idealismo irreverente: as crônicas de Oswald de Andrade e Nelson Rodrigues
}

\author{
Irreverent idealism: the chronicles of Oswald de Andrade and Nelson Rodrigues
}

Tiago LeITE Costa

Pontifícia Universidade Católica do Rio de Janeiro

-

\begin{abstract}
Resumo: O artigo visa cotejar as crônicas Telefonema (1944-54) de Oswald de Andrade e Confissões (1967-74) de Nelson Rodrigues e examinar a forma ímpar como se situam na tradição do gênero no Brasil. Trata-se de verificar pontos de aproximação e de distanciamento nos modos como cada um dos autores utiliza o idealismo e a irreverência como estilo crítico, analisando as contendas que travaram com artistas e intelectuais de suas épocas. Pretende-se mostrar que ambos, a despeito de suas incompatibilidades ideológicas, defenderam concepções similares da autenticidade nacional e sobressaíram-se como escritores extemporâneos na história da crônica brasileira.
\end{abstract}

Palavras-chave: Crônicas; Oswald de Andrade; Nelson Rodrigues.

\begin{abstract}
This paper aims to confront the chronicles "Telefonema" (1944-54) by Oswald de Andrade and "Confissões" (1967-74) by Nelson Rodrigues and examine the unique manner how they fit in the tradition of the genre in Brazil. This is about checking points of approximation and distancing in the ways by each one of the authors uses idealism and irreverence as a critical style, analyzing their strifes with artists and intellectuals of their times. The aim is to show that both, despite their ideological incompatibilities, supported similar conceptions of national authenticity and stood out as untimely writers in the brazilian chronicle's history.
\end{abstract}

Keywords: Chronicles; Oswald de Andrade; Nelson Rodrigues.

\section{Introdução}

Em um século e meio de existência, a crônica se tornou tão familiar ao cotidiano do leitor brasileiro que parece quase um gênero nativo. Muitos dos nossos melhores escritores fizeram incursão no formato, o que contribuiu para a sua ascendência entre nós.

Ainda assim, tradicionalmente, a crônica foi vista como literatura menor diante do romance e da poesia. Pelo seu caráter despojado, sempre pareceu imprópria para a abordagem dos temas universais e destinada ao passageiro.

Há algum tempo, em função da crescente desconfiança sobre as delimitações de gênero, a crônica vem suscitando maior atenção dos pesquisadores como objeto de estudo. Nela, as fronteiras entre objetividade $\mathrm{e}$ subjetividade, prosa e poesia sempre foram naturalmente móveis. Como observou Davi Arrigucci Jr:

(...) às vezes, a prosa da crônica se torna lírica, como se estivesse tomada pela subjetividade de um poeta do instantâneo, que, mesmo sem abandonar o ar de conversa fiada, fosse capaz de tirar o difícil do simples, fazendo palavras banais alçarem voo. Outras vezes, a tendência é para a prosa de ficção, pela ênfase na objetivação de um mundo recriado imaginariamente: ela pode se confundir com o conto, a narrativa satírica, a confissão (ARRIGUCI JR., 1987, p. 55).

A crônica vaga pela narração, descrição, digressão, argumentação e comentário. Ancorada numa inerente consciência metalinguística, ela faz uso da metáfora, hipérbole, personificação e ironia para retrabalhar os fatos que lhe chegam à mão. Essa mobilidade natural da crônica tem garantido a atualização do formato.

Além disso, muitos pesquisadores já ressaltaram o modo pelo qual a crônica registra sua época como uma espécie de fotografia escrita. Com efeito, ela tem sido uma fonte histórica preciosa, na qual ideias e costumes se revelam pelas fendas do discurso oficial. Na crônica, é possível captar o clima das cidades modernas retratado tanto nos grandes debates ideológicos quanto nas frivolidades cotidianas. 
Soma-se o fato de que, entre os escritores de primeira linha, o contexto que informa a crônica é igualmente pretexto para o exercício literário. A conjuntura então serve de trampolim para o mergulho autoral em águas profundas da experiência coletiva e privada de cada época.

Nesse quesito, Telefonema de Oswald de Andrade e Confissões de Nelson Rodrigues são exemplares. Por motivos diversos, nas fases finais de suas carreiras, tanto um quanto o outro cultivaram um espírito engajado e evocativo de um Brasil idealizado, que tentavam preservar da intervenção dos movimentos políticos e culturais das décadas de 1940/50 e 1960/70, respectivamente.

Ambos fizeram uso do episódico como subterfúgio para a discussão aguda sobre impasses éticos, políticos e estéticos da cultura brasileira. Mais do que isso, a linguagem combativa aliada à ambição sintática e semântica dos dois distinguem seus estilos do que se tornou a linha dominante no gênero, muito mais conciliatória, comedida e neutra.

Para ilustrar o argumento, vejamos as impressões de Vinícius Dantas e Luís Augusto Fisher sobre, respectivamente, as crônicas de Oswald e Nelson. A começar por Telefonema:

A linguagem desses "Telefonemas" está longe da simplicidade e despojamento da tradição brasileira da crônica. A crônica, na versão oswaldiana, não pretende se integrar no cotidiano, nele habitar com naturalidade, falando uma linguagem solta e simples para aproximar os homens numa momentânea comunidade lírica. Existe aí um ânimo teórico e uma agressividade especiais, de quem dispõe em sistema seus dados, procurando compreendê-los ideologicamente a partir de um remoto significado político mundial. Oswald não é um amante do miúdo, com o enleio de uma conversa fiada sedutora, escrita com oralidade e humanismo conservador (DANTAS, 2004).

Em seguida, o comentário de Luis Augusto Fisher sobre Confissões:

A reação de seu texto à consumação da massificação que conhecemos se torna mais visível em contraste com a crônica sua contemporânea - em boa parte das vezes autocomplacente, autocomiserativa, bem ao contrário de Nelson, que purga suas mazelas mais dementes em praça pública, oferecendo-se em sacrifício (e em espetáculo voyeur) para leitores que aceitem o desafio de nadar contra aquela maré, que em sua época era montante e que continua ativa até agora (FISHER, 2009, p. 321).

As passagens acima refletem traços do que acredito ser a paradoxal mistura de irreverência e idealismo que norteia as crônicas de Oswald e Nelson. Esse idealismo irreverente, ao mesmo tempo irônico e engajado, permite aos dois autores deslizar do trivial ao transcendente, e produzir textos que se ocupam dos dilemas coletivos a partir de um olhar e de uma linguagem extremamente pessoais.

A seguir, pretendo contrastar as escritas de Oswald de Andrade em Telefonema e Nelson Rodrigues em Confissões especificando a afinidade de suas defesas do que entendiam como a legítima cultura brasileira.

Defensores de matrizes ideológicas aparentemente opostas, Nelson e Oswald se aproximaram como escritores intempestivos em seus contextos. Acredito que a releitura de Telefonema e Confissões é relevante não apenas para a reconsideração dos papeis de Oswald e Nelson na história da crônica brasileira, mas também para o enriquecimento da fortuna crítica acerca do processo de modernização nacional.

\section{Telefonemas}

A associação de Oswald de Andrade e Nelson Rodrigues à renovação da dramaturgia moderna brasileira é senso comum no pensamento acadêmico. Com eles, o teatro nacional superou as defasadas convenções do século XIX e atualizou sua expressão à vanguarda do século XX. As afinidades, no entanto, não param por aí.

Ainda que filiados a ideologias opostas, suas ações como intelectuais revelam um surpreendente parentesco. Boa prova disso é a variedade de estereótipos incorporados às figuras de ambos no cenário cultural brasileiro. A alternância das imagens públicas dos autores é conhecida, mas não custa relembrar.

No caso de Oswald de Andrade, trata-se do trajeto em que o aristocrata antropófago dos anos 1920 tornou-se o comunista da década de 1930 e, por fim, o excêntrico e isolado veterano de 1940-50, que insistia em cultivar inimizades. Na última década de sua obra, Oswald renovou a antropofagia nas crônicas e ensaios, enxertando referências filosóficas e históricas nas intuições do manifesto modernista. Nesse período, Oswald escreveu a coluna Telefonema - sua atuação mais duradoura em jornal, 600 crônicas - na qual defendeu o retorno ao primitivismo nacional contra as teorias messiânicas que disputavam a hegemonia no mundo bipolarizado do pós-Guerra.

Por sua vez, as metamorfoses de Nelson Rodrigues também ficaram célebres. Sua persona oscilou entre antinomias desconcertantes: de vanguardista teatral a defensor do Regime militar; de autor maldito a conservador tradicionalista; de tarado obsceno a moralista. Atualmente, sua obra teatral goza da unanimidade que ele sempre desprezou. Mas suas crônicas Confissões ainda continuam controversas. Nelas, o autointitulado 
reacionário opõe o "Brasil profundo" dos subúrbios cariocas à utopia forasteira dos movimentos de esquerda.

Como nesse artigo irei me ater às crônicas derradeiras dos dois autores, cumpre então avançarmos na descrição do último Oswald de Telefonema e do último Nelson de Confissões. Começando por Oswald, é importante ter em mente que o escritor viveu na década de 1944-54 sem as referências que balizaram as polêmicas de 1920-30, ou seja, o modernismo e o comunismo. Como observa Vera Maria Chalmers:

A antropofagia filosófica no jornal foi uma aposta contra o vazio ideológico do presente, para alcançar um outro tempo virtual capaz de preenchê-lo de significação (...). Oswald escreve Telefonema para defender o saber irônico, e assim, paradoxalmente, fazer o elogio do tempo da crônica. (...) a causa a defender contra o (seu) tempo é a virtualidade da utopia antropofágica, a qual sustenta a possibilidade da referência a um tempo real e complexo, porque mobiliza simultaneamente o passado, o presente e o futuro (CHALMERS, 1996, p. 40).

A irreverência é o meio pelo qual Oswald procura fundir o passado ideal e o futuro utópico para realizar a crítica do presente indeterminado. Após a Segunda Guerra, com a Europa em ruína, o destino político e cultural do mundo estava teoricamente em aberto. A bomba atômica americana e a revelação da "Rússia bonapartista" despertaram grande desconfiança sobre os dois países que tomavam a dianteira da história. Diante disso, a antropofagia retorna estrategicamente para conceber alternativas às doutrinas setentrionais. Para Oswald, a visão de mundo dos trópicos era a opção natural ao "farisaico puritanismo americano" e ao "Dogma da Imaculada Revolução Russa” (1972, p. 120).

Em uma crônica de 1952, chamada justamente "Recomeçar", essa conjuntura fica bem delineada. A citação é longa, mas importante para esclarecermos de que modo se associam o engajamento, a imaginação romântica e a ironia na base do pensamento articulado em Telefonema.

Não se pode recomeçar sem participar. O jornal deixou de ser um neutro repositório de notícias e comentários para tomar uma posição ativa e vigilante (...). O romance reportagem está na ordem do dia. Não se pode mais cuidar de literatura abstrata, desligada do local e da hora.

Esta segunda metade do século XX cresceu de graves responsabilidades. Não se deve mais ser 'realista' como nos velhos tempos em que se exigia de criador de personagens e de situações a estrita objetividade, a imparcialidade, a desconversa.
Se o século XIX avançou até o ano 14, sabe-se que o que estamos assistindo é apenas a verificação dos resultados inflexíveis do jogo de dados que naquele ano começou entre o jovem imperialismo germânico e o medalhado tigrismo inglês.

Hoje, os imperialismos mudam de paralelo e de consciência. Não são mais comunidades gulosas que se enfrentam, e sim concepções de mundo.

Com Malaparte, Sartre, Camus e o americano Henry Miller, vemos todos os quadrantes da literatura tomarem o colorido que convém ao Brasil, este velho país sem pecados, sem remorsos e portanto sem culpa.

Tanto aos que recomeçam como aos que começam, interessa ligarem-se a essa terceira frente que se opõe tanto ao urso soviético como ao tamanduá yankee.

Viva o Brasil! Como se grita no fim das festas sérias (ANDRADE, 1996, p. 333).

A passagem é toda muito sugestiva. A começar pelo título. Não apenas o mundo recomeçava naquele momento, mas também Oswald. Depois de uma década (os anos 1930) de atividades praticamente clandestinas, ele procura se reposicionar no tabuleiro do debate cultural defendendo uma literatura sem metafísica "abstrata, desligada do local e da hora", nem realismo de "estrita objetividade, imparcialidade". Com isso, Oswald estava reivindicando a primazia brasileira em face do existencialismo europeu em voga nos anos 1940-50. Para ele, cabia a nós, que sempre nos sentimos em casa no ilógico e no absurdo, que nunca divisamos bem onde era o paraíso e onde era o inferno, tomar a dianteira na demolição das dicotomias do pensamento ocidental por meio da imaginação literária ${ }^{1}$.

Nesse ponto, é importante especificar melhor quais eram as particularidades nacionais que definiram o engajamento de Oswald nas crônicas. Para isso, é importante lembrar que, no espaço de tempo que separa o Manifesto Antropófago de 1928 dos Telefonemas de 1944-54, surgiu uma obra que revolucionou a autoimagem do Brasil: Casa-Grande e Senzala. O livro de Gilberto Freyre apresentou um retrato secreto da nossa história, em um viés inédito, que levou ao colapso as teses positivistas que ainda justificavam o desprezo do intelectual brasileiro pelo Brasil.

À parte toda controvérsia que gerou (e gera), Casa-Grande contribuiu para uma nova idealização do

\footnotetext{
${ }^{1}$ Em crônica de 1947, intitulada Por uma recuperação nacional afirma Oswald: "E nós que temos em casa a opulência de uma civilização primitiva das melhores. Que temos a invenção do Nheengatu, divulgada por Amorim Brandão, donde Mário de Andrade tirou a sintaxe do Macunaíma, nós que temos o maravilhoso na reportagem dos cronistas e dos missionários, que possuímos Aleijadinho e Villa-Lobos, que levamos a Antropofagia às consequências profundas da revolução modernista, vamos ajoelhar no Café de Flore, diante de Sartre e Simone Beauvoir Vivemos Fakirizados pelo estrangeiro" (ANDRADE, 1996, p. 212).
} 
caráter nacional ao revelar predicados insuspeitados da miscigenação brasileira. Tais qualidades tinham como referência não o racionalismo científico ou códigos vitorianos de conduta, mas a plasticidade lusotropical, com sua espontaneidade, sua solidariedade, seu sentimentalismo, sua criatividade para lidar com condições adversas etc. O raciocínio de Gilberto atualizava a concepção romântica, segundo a qual cultura e civilização representam valores antinômicos. A promessa de redenção pela originalidade da cultura mestiça tropical influenciou declaradamente o retorno de Oswald à antropofagia.

O recomeço, entretanto, será autocrítico e irônico. Como explica na crônica mencionada, os imperialismos "não são mais comunidades gulosas que se enfrentam, e sim concepções de mundo". Portanto, a antropofagia volta a ser relevante como operador conceitual orientado para a elaboração de uma visão de mundo brasileira, na qual as virtudes tropicais formam o contraste imediato com a decadência da civilização do norte. Porém, à diferença do ufanismo do Conde de Afonso Celso, a irreverência relativiza o patriotismo. "Viva o Brasil! Como se grita nas festas sérias".

Na verdade, a antropofagia de 1928 já praticava essa estratégia. Todavia, a chegada de Casa-Grande minuciou e patenteou a oposição de valores entre a cultura mestiça nacional e o progresso racionalista no qual rezava a cartilha do intelectual brasileiro. Além disso, o ensaio de Gilberto avançou nas ambições estéticas modernistas ao romantizar a linguagem sociológica, por meio de uma prosa mista, sedutora e bem humorada. Oswald reconhece isso em vários Telefonemas ${ }^{2}$. Mas é interessante, também, percebermos o caminho inverso. Isto é, como a antropofagia já influenciara Freyre. Sobre isso, José Guilherme Merquior comenta que:

A "sociodicéia" brasileira necessitava de outros conceitos - requeria um manejo muito mais livre da categoria de cultura. Para dizê-lo de modo amplo: a legitimação intelectual do Brasil, aos olhos dos brasileiros, dependia da possibilidade de empregar a ideia de cultura nacional como um valor em vez de objeto de análise. Por isso, o único indício ideológico que valida plenamente o Brasil, antes do resgate histórico antropológico conduzido por Gilberto, seria a Antropofagia, o movimento-manifesto de Oswald de Andrade. (MERQUIOR, 1990, p. 347).

\footnotetext{
A crônica Por Gilberto de 1946 exemplifica nosso argumento: "Se há ainda alguma coisa que salva este país, é a literatura. E a obra-prima de Gilberto transcende da sociologia e da crítica para esplender nisso que se pode moderna e realmente chamar de literatura. Quando eu era comunista de varal, fiz todas as restrições canônicas ao livro de Gilberto. Achei-o hesitante, não concludente, semivisionário, semirreacionário e classifiquei-o de joia da sociologia afetiva. Minha experiência pessoal me conduziu agora a crer, com o admirável Camus, que nada há de mais odioso que o pensamento satisfeito e a obra que prova. Nada mais odioso que a tese na obra de arte.” (TEL, 1996, p. 200-201).
}

É notório que a ideia de cultura nacional construída pela antropofagia é transitiva e hostil à xenofobia provinciana. Por outro lado, Oswald era terminantemente avesso ao complexo de inferioridade étnico-cultural alimentado pela intelectualidade cosmopolita. Para fugir de ambos os tentáculos da intelligentsia nacional, Oswald reafirma a toda hora sua autonomia em relação aos proselitismos. Assim, a metralhadora giratória de Telefonema aponta para o formalismo da geração de 1945 e a estreiteza dos romancistas de 1930; mira nos comunistas e alfineta os antigos parceiros modernistas; além, é claro, de disparar fogo contra seu alvo preferido: políticos e intelectuais conservadores de todas as espécies.

A utopia oswaldiana profetizava que uma futura supremacia da cultura sobre os poderes militares e econômicos iria ultrapassar o capitalismo e o comunismo na direção de uma sociedade global e sincrética. Daí sua polêmica com aqueles que ainda apostavam na desmoralizada civilização europeia, no mecanicismo americano e no dogmatismo soviético.

\section{Confissões}

Oswald morre em 1954. Uma década depois, nada daquilo que projetara havia ocorrido. Ao contrário, a Guerra Fria encontrava-se no auge, motivando golpes militares ao redor do mundo, entre os quais o Golpe de 1964.

No Brasil, a ditadura foi capitalista e de direita. Fato que, se não explica, certamente justifica a ampla hegemonia do pensamento de esquerda nos ciclos intelectuais do país. Na época, Roberto Schwarz observava que: "Nos santuários da cultura burguesa a esquerda dá o tom. Esta anomalia é o traço mais visível do panorama cultural brasileiro entre 1964 e 1969." (1978, p. 62).

Nesse cenário, Nelson Rodrigues assume um novo personagem. As suas Confissões revelam o lado reacionário que, segundo ele, mantinha em segredo perante a maioria progressista dos letrados brasileiros. Nas crônicas, promove uma campanha implacável contra os seus pares, amparada numa argumentação conservadora e profundamente irônica com a revolução dos costumes e os ideais socialistas.

De modo geral, o diagnóstico das Confissões era o de que o mundo perdia a transcendência no amor, na religião, na arte, no conflito de gerações e assim por diante. Nelson acreditava que privado do mistério, do tabu e da hierarquia, o homem se degradava. Além disso, outra ameaça constante era a derrocada do indivíduo diante dos movimentos coletivos. Lamentava o desaparecimento da figura romântica do autor na "torre de marfim" e responsabilizava a politização da arte pelo eclipse da autonomia literária. Em crônica de 1970, dizia: 
Só as gerações românticas é que exigiam do romancista $\mathrm{o}$ ato literário puro. $\mathrm{O}$ autor tinha que ser autor mesmo. Ninguém aceitaria um Dumas Filho sem A dama das camélias ou um Dickens sem David Copperfield, ou um Victor Hugo sem Os miseráveis. Mas os tempos rolaram e eis que nossa época inventou o "intelectual de passeata". Perguntará o leitor: - "E o que faz 'o intelectual de passeata?'. Hoje não faz nada. Mas houve um tempo em que fazia exatamente passeata (...).

Um Gilberto Freyre é um escândalo em nossa literatura. É o grande artista que jamais abandona a sua formidável solidão criadora. Nunca se aviltou em passeatas. Gilberto Freyre é o puro autor, o mais autor dos nossos autores. Outro: - Guimarães Rosa. O mundo, para ele, era sua obra. Punha uma frase bem sucedida acima de todo o Sudeste Asiático. Dirá um "intelectual de passeata" que isso é monstruoso. Monstruoso coisa nenhuma. Gilberto Freyre tem toda uma obra miguelangesca sobre o Brasil e seu povo. Também Guimarães Rosa só tratou do Brasil, só tratou de nós (RODRIGUES, 2002c, p. 129).

Mais do que os movimentos coletivos, era o próprio processo de modernização da sociedade brasileira que o indignava. Suas crônicas pulsam na nostalgia de uma época da inocência, portadora de um código de valores que havia se perdido. $\mathrm{Na}$ impossibilidade de retorno do passado, Nelson contrapõe arquétipos da cultura brasileira ao projeto de nação da intelectualidade progressista.

Na maior parte das vezes, a premissa é a de que a elite culta desconhecia os hábitos, paixões e crenças do brasileiro comum. Acusava as "esquerdas" de se utilizarem da miséria para se promoverem, incitando a luta de classe num povo supostamente fraterno e cortês, capaz de fazer piada da própria desgraça.

O senso de humor, aliás, parecia-lhe uma virtude tipicamente nacional. Nelson alimentava o mito da democracia "à brasileira", talhada na gentileza e no calor humano do nosso povo: "O brasileiro é o único povo que faz piada. Se não temos um vampiro, estejam certos: - é a piada que torna inviável qualquer Drácula brasileiro" (2002a, p. 31). Além da dimensão civilizatória, destacava o aspecto redentor da jovialidade nacional: "Um povo que conserva, no subdesenvolvimento, um humor gigantesco, é miserável, mas não é derrotado" (2002a, p. 108).

Essas eram dimensões da cultura brasileira que Nelson achava que fugiam ao horizonte do pensamento da esquerda nacional. Por isso considerava que a revolta e a politização promovidas por aqueles intelectuais eram antipatrióticas e alheias ao verdadeiro espírito do brasileiro. Em uma crônica de 1972, comenta:

Num domingo recente saiu um imenso ensaio, quase uma página inteira, em corpo seis. Seu autor era, justamente, uma flor das esquerdas. E metia o pau no
Chacrinha, e não só no Chacrinha: - também na música popular, na escola de samba, no Chico Buarque, no Fla-Flu e, por fim, no sexo.

$\mathrm{O}$ esquerdista negava tudo o que o brasileiro adora. Li aquilo e saí perguntando: - "Você gosta de sexo? De música popular? De futebol? E de repente, relendo o tal artigo, percebi porque nossa esquerda não se comunica com ninguém e vive na mais obtusa solidão. Repito: - a nossa esquerda só fala, escreve, gesticula e só doutrina para si mesma (RODRIGUES, 2002b, p. 120).

Ao lado do descaso com os costumes locais, também lhe incomodava a subserviência do artista e do intelectual brasileiro aos modelos estrangeiros. Nelson era revoltado com o nosso sentimento de inferioridade, para o qual cunhou o célebre epíteto "complexo de vira-latas". Nesse tópico, muitas vezes, o seu patriotismo deixou de ser apenas uma crítica irreverente à intelectualidade de esquerda e se alinhou ao discurso ufanista do Regime militar.

Um detalhe importante é que mesmo nos momentos de maior euforia nacionalista, Nelson acreditava que a redenção do país seria o trabalho de algumas grandes individualidades nas quais o povo identificaria suas potencialidades. O protagonismo, entretanto, não tinha exclusividade de classe. Ele poderia ser encenado por qualquer um (artista, político, intelectual, empresário, religioso etc.). Porém, aonde Nelson enxergava sua utopia particular com mais frequência era nos jogadores da seleção brasileira.

Exatamente por virem do povo é que os jogadores brasileiros poderiam cevar as esperanças da nação. Só as "esquerdas", que achavam que o futebol era o ópio do povo, não se reconheciam no escrete. Com a seleção, dizia ele, o Brasil deixava de ser "um vira-lata entre as nações" (2002a, p. 151). Não há dúvida de que aqui a idealização patriótica assume suas frequências mais altas e o sarcasmo cede espaço a um civilismo épico.

A historiadora Adriana Facina, ao propor uma análise antropológica da obra de Nelson Rodrigues, conclui sobre sua "forte inspiração numa matriz romântica de pensamento" (2004, p. 295). Ela justifica seu raciocínio argumentando que, embora a "antropologia rodriguiana" seja fundamentalmente pessimista:

Há, porém, uma brecha nesse pessimismo no "triunfo do homem" e da bondade humana que Nelson enxergava como resultado da identificação de todo um povo com os jogadores da seleção. Se o amor poderia salvar os indivíduos, o gênio individual, quando encarnasse o caráter e o destino de um povo, poderia redimir toda uma coletividade. Essas ideias podem ser vinculadas, a meu ver, a uma matriz de pensamento romântica que tem a noção de cultura (Kultur) como eixo central. A 
descrença na capacidade da razão em tornar os seres humanos melhores e mais felizes, assim como a aposta na redenção humana via sentimentos seja pelo amor, seja pela paixão nacionalista despertada pelo escrete, essas são algumas das características fundamentais desse romantismo que marca a visão de mundo de Nelson Rodrigues (FACINA, 2004, p. 305).

$\mathrm{O}$ argumento de Facina serve de ponte para retomarmos as analogias entre Nelson Rodrigues e Oswald de Andrade que fundamentam a hipótese desse artigo. Assim, podemos começar observando que, como em Telefonema de Oswald, o romantismo subjacente às Confissões de Nelson vincula-se à premissa de diferenciação entre cultura e civilização.

Aqui é necessário um aparte. A distinção moderna entre civilização e cultura, que germina no Sturm und Drang do XVIII e se consolida no Romantismo alemão do século XIX, é um tópico enorme que seria impossível de se aprofundar sem fugir ao tema central. Interessa, portanto, alguns aspectos do problema em função do modo como aparecem nas crônicas de Oswald e Nelson.

Dito isso, cabe retomar algumas particularidades da oposição civilização x cultura apontadas por Norbet Elias no seu clássico $O$ Processo Civilizador. De acordo com Elias, embora a noção de civilização abarque inúmeras acepções, é possível distinguir uma "função geral" para todos os significados, segundo a qual civilização: "expressa a consciência que o Ocidente tem de si mesmo. Ela resume tudo em que a sociedade ocidental dos últimos dois ou três século se julga superior a sociedades mais antigas ou a sociedades contemporâneas 'mais primitivas"” (ELIAS, 1990, p. 23).

Elias explica que o conceito de cultura forjado pelo Romantismo alemão como antítese da ideia iluminista de civilização, procurava fazer frente à hegemonia francesa e inglesa do século XIX, sustentando a relativa superficialidade do valor das atividades ligadas à ideia de civilização perante a profundidade daquelas relacionadas ao domínio da cultura. Enquanto a primeira se reduzia à esfera das meras realizações técnicas a segunda moldava o verdadeiro caráter de um povo.

Da perspectiva romântica, a civilização reflete o processo racional e universal de algo que estaria em movimento constante e para frente; ao passo que a cultura implicaria relação diferente com o tempo, mais ligada à continuidade com um passado que informa a singularidade de um povo, expressa nas obras de arte, religiões, tradições etc.

Em resumo, nas palavras de Elias:

Até certo ponto, o conceito de civilização minimiza as diferenças nacionais entre os povos (...). Enquanto o conceito de civilização inclui a função de dar expressão a uma tendência continuamente expansionista de grupos colonizadores, o conceito de Kultur (cultura) reflete a consciência de si mesma de uma nação que teve de buscar e constituir incessantemente e novamente suas fronteiras, tanto no sentido político como espiritual, e repetidas vezes perguntar a si mesma: "Qual é, realmente, nossa identidade?” (ELIAS, 1990, p. 25).

Sabemos que, no Brasil, as condições sociais e intelectuais que motivaram o surgimento e as significações do Romantismo foram distintas das europeias. Principalmente porque a importação do sentimentalismo e da idealização do passado não significou entre nós uma reação ao desencantamento iluminista do mundo.

Apesar disso, nas inúmeras manifestações da "dialética do localismo e do cosmopolitismo" (CANDIDO, 1967) que, desde então, definiu o pensamento moderno brasileiro, é incontestável que a defesa da cultura nacional frente à importação dos modelos civilizatórios estrangeiros é uma insígnia do nosso paradigma romântico. Foi com os românticos que passamos a perguntar sistematicamente "qual é nossa identidade?" e responder valorizando (ou idealizando) a cultura local.

Assim sendo, no artigo Civilização e dinheiro, de 1949, Oswald de Andrade parece recorrer exatamente à dicotomia romântica à qual nos referimos para alertar sobre a necessidade de combater os agentes domésticos que estariam desagregando nossa cultura.

À cultura podem-se ligar dois conceitos: o de sentimento e o de caráter. A civilização, dois outros: o de razão e o de técnica. Cultura é o que somos. Civilização é o que realizamos. Assim sendo, Cultura vem a ser a alma de um povo, de uma etnia, de uma área histórica. Civilização, ao contrário, é espírito, é política, é técnica. Aquela é Pathos esta é Logos. Moisés foi o criador de uma cultura milenar. Descartes, um iniciador de civilização.

(...) Cultura é língua, folclore e comida, vestuário e religião, enfim, o que dá originalidade a um grupo étnico e a sua área geográfica. Civilização é matemática, water-closet, libertação de preconceitos, rádio, esperanto, divórcio, leis sociais. A índia tem Cultura e não tem Civilização. Nos Estados Unidos sobra Civilização e se desmancham Culturas. No Brasil andam aos pontapés Civilização e Cultura. Da civilização nos refastelamos no pior. E da Cultura que há quatro séculos procura dar-nos um caráter de povo lírico, cordial e estoico destruímos implacavelmente as sobras, liquidando o índio, sofisticando o negro e monogamizando o português. (...) se nós brasileiros continuarmos indiferentes e amáveis ante os costumes tanto políticos como domésticos que nos distinguem, veremos confirmar-se o calamitoso diagnostico de que perdemos nossa Cultura sem chegar a ter uma Civilização (ANDRADE, 1991, p. 203). 
Minha hipótese é a de que a antítese descrita por Oswald também fundamenta o discurso de Nelson Rodrigues, embora este apresente matizes certamente mais conservadoras. Ainda assim, ao bater de frente com o discurso progressista das esquerdas, Nelson também recorreu aos protótipos românticos do que seria a genuína cultura nacional, mesclando idealismo e irreverência em um discurso singular dentro da tradição da crônica nacional.

\section{Conclusão}

Oswald foi uma figura polêmica na intenção de se contrapor às disposições estéticas e políticas conservadoras de sua época. Nelson tornou-se uma figura polêmica na defesa de um pensamento conservador contra o que considerava o progressismo alienado dos intelectuais da década de 1960/70. Malgrado as diferenças, ambos foram cronistas dissonantes, que lançaram mão de uma linguagem pungente e irônica para a defesa de concepções românticas da identidade nacional contra as ideias hegemônicas de seus tempos.

Dispares, à primeira vista, de imediato é possível associá-los quanto ao uso da ironia e da polêmica como estilo crítico. Ainda que movidos por razões diversas, cultivaram uma escrita combativa, paradoxal e profética, por meio da qual buscaram o choque com o meio intelectual de seus contextos.

Desse aspecto, fugiram aos caracteres hegemônicos da crônica nacional, a saber: o trato leve, o humor elusivo e a recusa à militância declarada. Como observou Antonio Candido sobre a fixação do gênero no Brasil: "deixando de ser comentário mais ou menos argumentativo e expositivo para virar conversa aparentemente fiada, foi como se a crônica pusesse de lado qualquer seriedade" (1992, p. 17).

$\mathrm{Na}$ contramão dessa tendência, Oswald e Nelson fizeram de suas crônicas verdadeiras tribunas. Nelas, a argumentação é sempre incisiva, com tom agônico e sarcástico. Nada é furtivo, pois fazem questão de alimentar o debate ideológico nos fatos aparentemente mais inofensivos. Aspiravam interferir na arena política e cultural brasileira e recusavam a postura descompromissada e um tanto contemplativa da crônica.

O idealismo irreverente, portanto, foi a ferramenta que serviu ao engajamento de ambos nos inúmeros assuntos dos quais se ocuparam. No período entre 1944 e 1954, em que Oswald de Andrade escreveu as crônicas Telefonema no Correio da Manhã, e entre 1967 e 1974, em que Nelson Rodrigues escreve as Confissões em O Globo, os dois utilizaram uma estratégia equivalente no combate a seus contemporâneos. $\mathrm{O}$ expediente consistia em defender certas noções de identidade nacional contra influências estrangeiras e correntes ideológicas internas opostas ao que entendiam como sendo o Brasil e o brasileiro mais autênticos.
Oswald e Nelson foram interpretes extemporâneos de seus respectivos contextos. Na raiz da verve típica dos autores, havia, a despeito de tudo que os distancia, um traço comum: aquilo que identificavam como o Brasil e o brasileiro ideais. Apesar das diferentes trajetórias e inclinações políticas, nas crônicas finais, Oswald e Nelson assemelharam-se na adesão à matriz romântica, perceptível nas imagens que projetavam do Brasil e de si mesmos como autores em conflito com seus tempos.

\section{Referências}

ANDRADE, Oswald. Telefonema. São Paulo: Globo, 1996. Estética e politica. São Paulo: Globo, 1991. 1990 Dentes do dragão, Os - entrevistas. São Paulo: Globo,

ARRIGUCI JR, David. Enigma e comentário: ensaios sobre literatura e experiência. São Paulo: Companhia das Letras, 1987.

CANDIDO, Antonio. Literatura e sociedade. São Paulo: Nacional, 1967.

A vida ao rés-do-chão. In: $A$ crônica: o gênero, sua fixação e suas transformações no Brasil. Campinas: Ed. Unicamp; Rio de Janeiro: Fundação Casa de Rui Barbosa, 1992. USP, 2002

O romantismo no Brasil. São Paulo: Humanitas FFLCH/

COSTA, Tiago. O perfeito cozinheiro das teorias deste mundo: a antropofagia ensaística de Oswald de Andrade. Rio de Janeiro: Garamond, 2014

DANTAS, V. O canibal e o capital - a arte do Telefonema de Oswald de Andrade. In: Terceira margem online. UFRJ, Rio de Janeiro, 2004. Disponível em: $<$ http://www.ciencialit.letras.ufrj. br/terceiramargemonline/numero12/xix.html > . Acesso em: 20 nov. 2015

ELIAS, Norbert. O processo civilizador - uma história dos costumes. Rio de Janeiro: Jorge Zahar, 1990.

FACINA, Adriana. Santos e Canalhas - uma análise antropológica da obra de Nelson Rodrigues. Rio de Janeiro: Civilização Brasileira, 2004.

FISHER, Luís Augusto. Inteligência com dor: Nelson Rodrigues ensaísta. Porto Alegre: Arquipélago editorial, 2009.

MERQUIOR, José Guilherme. Crítica 1964-1989: ensaios sobre arte e literatura. Rio de Janeiro: Nova Fronteira, 1990.

RODRIGUES, Nelson. A cabra vadia, novas confissões. São Paulo: Companhia das Letras, 2001a.

Flor de obsessão. São Paulo: Companhia das Letras, 2002a.

Óbvio ululante. São Paulo: Companhia das Letras, 2002b.

O reacionário. São Paulo: Companhia das Letras, 2002c.

Oremador de Ben-Hur. São Paulo: Companhia das Letras, 2002d.

SCHWARZ, Roberto. O pai de família e outros estudos. Rio de Janeiro: Paz e Terra, 1978.

Recebido: 30 de dezembro de 2015 Aprovado: 25 de maio de 2016 Contato: tiagoleite79@gmail.com 